\title{
O Retrato da Condessa de Casa Flores de Francisco de Goya y Lucientes
}

\author{
Ana Carolina Dias Florindo ${ }^{1}$ \\ DOI 10.20396/eha.vil4.3354
}

Introdução

Essa apresentação é proveniente da pesquisa de iniciação científica que tenho realizado ao longo do ano de 2019, com o financiamento da FAPESP, sob orientação do Prof. Dr. Jorge Coli e co-orientação de Letícia Badan Palhares de Campos. A pesquisa visa analisar a pintura Retrato da condessa de Casa Flores, um óleo sobre tela, produzido entre 1790 e 1797, por Francisco José de Goya y Lucientes - durante o momento de maior produção de retratos pelo artista. Se encontra localizada atualmente no acervo do MASP (Museu de Arte de São Paulo Assis Chateaubriand), como parte da exposição Acervo em Transformação. O objetivo central do trabalho é o estudo da pintura, por meio da identificação da figura retratada, sua relevância para o contexto espanhol do momento, bem como a compreensão do espaço que o retrato ocupa dentro da vasta produção artística de Goya, como também a maneira pela qual a figura feminina é representada em outras obras do pintor. Para tanto, procura-se aprofundar o trabalho iconográfico e histórico, com o auxílio de uma bibliografia e fontes primárias, a fim de compreender o momento e motivos que levaram Goya à realização do retrato, assim como a reconstrução da trajetória da obra até sua chegada ao museu e o lugar que ocupa atualmente no MASP.

Antes de analisar a pintura, foi necessário compreender um pouco mais sobre quem era seu idealizador. O pintor Francisco de Goya y Lucientes nasceu em Fuendetodos, Aragão, na Espanha, em 30 de março de 1746. Ele passa sua infância no mesmo local, mudando-se para Saragoça alguns anos mais tarde; aos 14 anos Coya se torna aprendiz do pintor Don José Luzán y Martinez, no trabaIho de copista de pinturas, tendo o primeiro contato com as obras de arte. Com 17 anos, Francisco se muda para Madri para estudar com Anton Raphael Mengs, pintor popular da realeza espanhola no momento. Em 1773 Coya se casa com Josefa Bayeu, com quem tem seis filhos, porém apenas um so-

1 Estudante de graduação do Instituto de Filosofia de Ciências Humanas da Universidade Estadual de Campinas. A pesquisa de iniciação científica descrita no texto foi financiada pela Fundação de Amparo à Pesquisa do Estado de São Paulo. 
brevive. ${ }^{2}$ No ano de 1774 o artista é convidado para trabalhar na Manufatura Real de Santa Bárbara, realizando canvas utilizadas na confecção de tapeçarias. ${ }^{3}$ Apenas em 17800 artista é eleito como um membro da Academia de Belas Artes de Madri, onde em 1785 pinta o primeiro quadro destinado à um membro da realeza: o Retrato da Duquesa de Osunã (1785). ${ }^{4}$ Ao começar a ganhar reconhecimento por seus desenhos e quadros, Goya deixa seu emprego na Manufatura Real para trabalhar como pintor do rei, produzindo retratos e outras obras para grande parte da nobreza e burguesia espanhola.

Em 1792, Goya é acometido por uma doença, até hoje de causa incerta, que o deixa surdo e debilitado; após sua recuperação, começa a produzir gravuras marcadas por aspectos sobrenaturais e imaginativos, de nome Los Caprichos (1797-1798). O artista se retira da vida pública em 1815, porém não para de produzir; as pinturas que elabora neste momento carregam aspectos de denúncia e descontentamento com a situação atual do país intituladas Los Desastres de la Guerra (1810-1815). Goya volta a adoecer em 1819, com causa também desconhecida; após a doença, o pintor se volta novamente para os elementos sobrenaturais e produz as Pinturas Negras (1819-1823) nas paredes de sua residência, Quinta del Sordo. Francisco de Goya y Lucientes morre aos 82 anos, em 16 de abril de 1828, em Bordeaux, na França.

\section{O Retrato da Condessa de Casa Flores}

O Retrato da Condessa de Casa Flores é um óleo sobre tela de grandes dimensões (113×79,5×2,5 cm), e se encontra atualmente em exibição no museu, parte da exposição Acervo em Transformação. Segundo as informações fornecidas pelo próprio museu, o quadro foi adquirido por meio de doação da Família Morganti, no ano de 1949.

A tela exibe a Condessa de Casa Flores (figura 1) sentada em uma cadeira de encosto dourado, adornada por um tecido azul. Trajada em um vestido longo, de cor branca, de aspecto aparentemente simples, com uma faixa de fita rosa logo abaixo do busto, e mangas até os cotovelos, com detalhes ao final de um laço rosa em cada braço; os laços em rosa são os únicos adornos presentes na vestimenta. O vestido é parte de uma moda um tanto comum no final do século XVIII, com o nome de estilo Império, que ganhou fama após a Revolução Francesa. A Condessa possui cabelos

\footnotetext{
2 Sua esposa falece em 1812.

3 Permanece nesta ocupação até 1792.

4 HUGHES, Robert. Goya. São Paulo: Companhia das Letras, 2007.
} 
escuros, da cor marrom e encaracolados, que chegam à altura de seu busto. As feições dela se encontram tranquilas, com um nariz reto, boca rosada e olhos castanhos. Ela senta com uma coluna ereta, porém seu corpo não se encontra rígido, concedendo ao observador a impressão de que está confortável em sua acomodação, com uma das mãos repousando sobre o colo, enquanto o braço direito se mostra levemente apoiado no encosto lateral da cadeira, que é ocultado pela saia do vestido; a vestimenta também oculta seus pés, que não são retratados.

A Condessa olha diretamente para o observador. Suas feições tranquilas parecem observar o espectador com a mesma serenidade expressa, algo inovador para a pintura da figura feminina - podemos atribuir este fato a modificação do lugar que as mulheres espanholas passaram a ocupar na sociedade no momento em que o quadro foi pintado, conquistando um espaço maior de pertencimento na vida pública. Em Francisco Coya, Rose-Marie Hagen e Rainer Hagen abordam este acontecimento afirmando que "muitas das majas, condessas e duquesas de Goya parecem expressar essa marcialidad, o [ato de] falar livremente sem corar, discutindo todos os temas de interesse e abolindo antiquadas ideias de respeitabilidade. Olham friamente para o espectador, como se a informarem que não permitirão qualquer restrição de seus actos". ${ }^{5}$

O fundo do quadro é composto por cores marrons, beges e leves toques de amarelo, que não se destacam. A imagem não apresenta nenhum objeto além da cadeira na qual a retratada repousa, colocando assim todo o enfoque da obra na figura da Condessa. Por não possuir elementos que se destaquem, a parte do quadro que se encontra atrás da Condessa auxilia em um realce da figura retratada, acontecimento que pode ser observado em outros retratos femininos produzidos pelo pintor, como o retrato da Marquesa de la Solana (1794-1795), Francisca Sabasa y Garcia (1804-1808) e A Condessa de Chinchón (1800) - a última apresenta uma vestimenta de cor semelhante à da Condessa de Casa Flores, mas é retratada com mais ornamentos, como um chapéu e anéis em suas mãos. Os quatro retratos possuem cores escuras em seus fundos, com o intuito pressuposto de colocara ênfase na figura retratada e guiar o observador a identificar os detalhes presentes na retratação dessas ilustrações.

O projeto tem como base a análise que se foca na compreensão da retratação da figura feminina pelo pintor na obra selecionada, para assim compreender a figuração feminina dentro da produção de Goya. Para estudar tal representação da figura feminina na obra da Condessa, foi necessária a comparação da pintura com outros retratos femininos produzidos pelo pintor, de modo a

5 HAGEN, Rainer. MARIE, Rose. Francisco Goya: 1746-1828. Colônia: Taschen, 2005. 


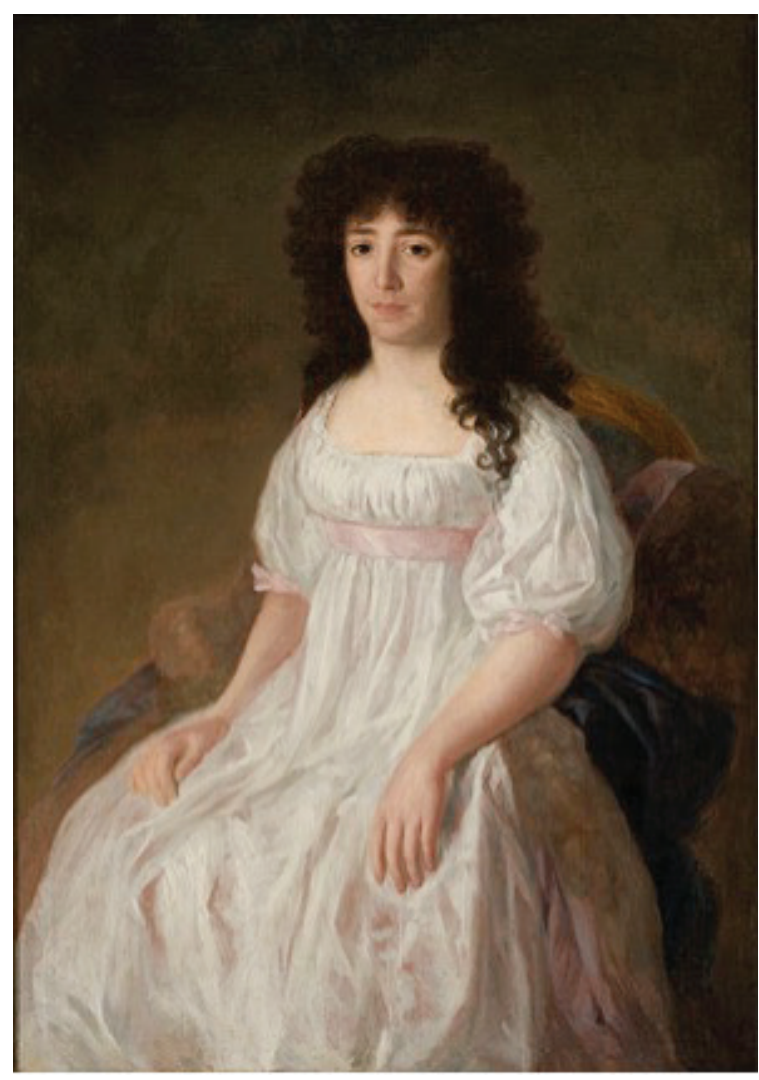

\section{[Figura 1]}

Francisco de Coya y Lucientes.

O Retrato da Condessa de Casa

Flores. 1790-1797.

Óleo sobre tela, $113 \times 79,5 \times 2,5 \mathrm{~cm}$.

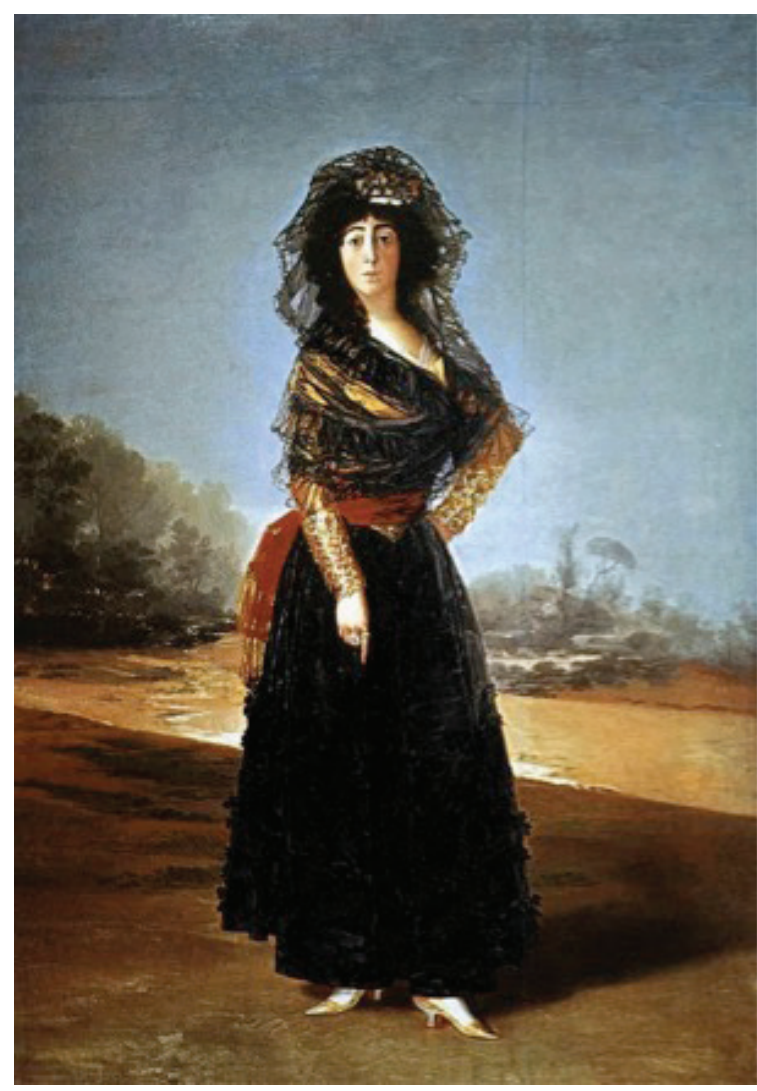

[Figura 2] Francisco de Coya y Lucientes. Retrato da Duquesa de Alba de Negro. 1797.

Óleo sobre tela, $210 \times 148 \mathrm{~cm}$.

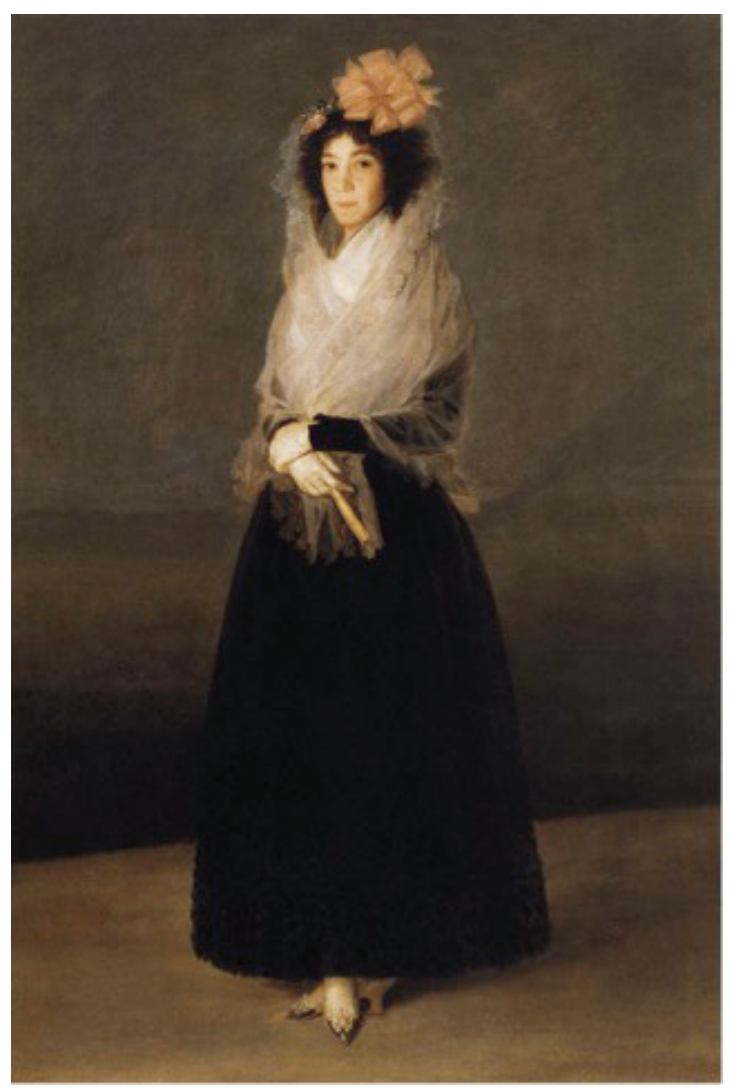

[Figura 3] Francisco de Goya y Lucientes. A Marquesa de la Solana; 1794-1795.

Óleo sobre tela, 181×122cm. 


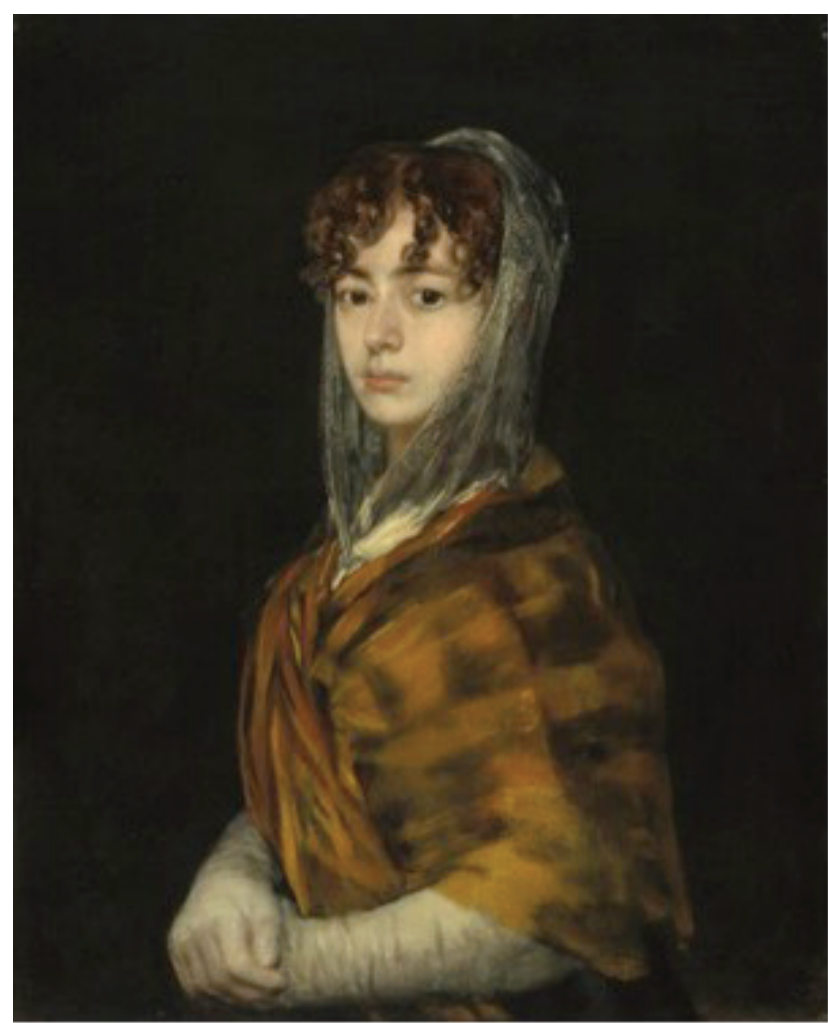

[Figura 4] Francisco de Goya y Lucientes. Francisca Sabasa y Garcia. 1805.

Óleo sobre tela, $71 \times 58 \mathrm{~cm}$.

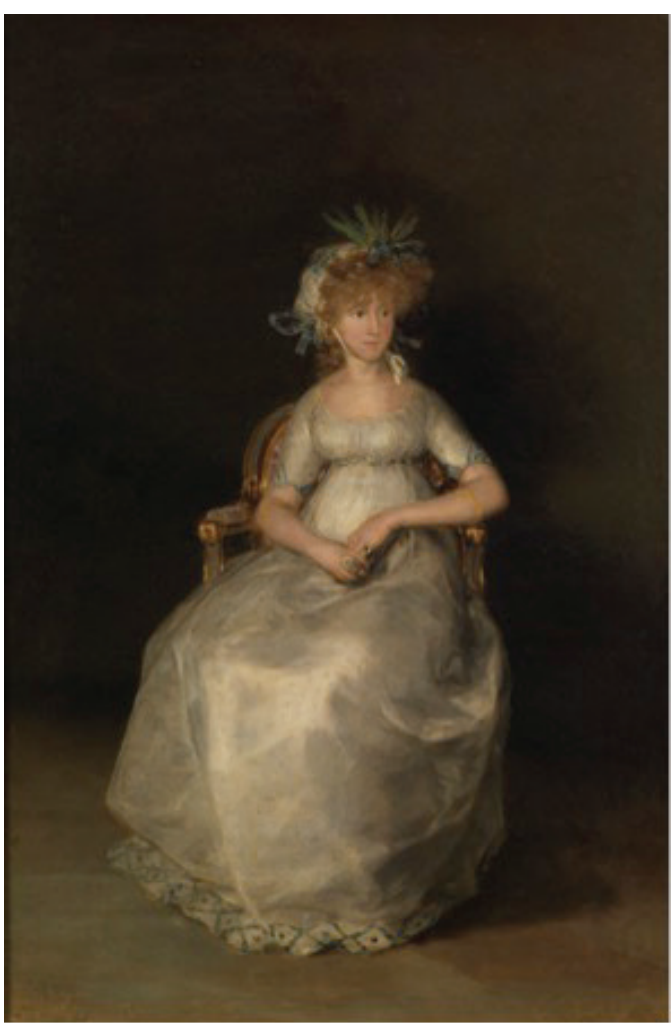

[Figura 5] Francisco de Goya y Lucientes. A Condessa de Chinchón. 1800.

Óleo sobre tela, 216x144cm.

elaborar uma análise comparativa. Para esse estudo, foram selecionados quatro retratos: o Retrato da Duquesa de Alba de Negro, 1797 (figura 2), A Marquesa de la Solana, 1794-1795 (figura 3), Francisca Sabasa y García, 1804-1805 (figura 4) e A Condessa de Chinchón, 1800 (figura 5).

\section{Documentação da obra}

Dessa maneira, precedente à análise da obra, foi necessário levantar informações referentes a essa obra produzida por Goya, que até o momento não foi alvo de pesquisas empíricas. No livro Goya as Portrait Painter, de Aureliano de Beruete, publicado em 1922, encontrou-se uma menção ao retrato da "Marquesa de Casa Flores" dentre a lista de pinturas realizadas por Goya elaborada por Aureliano. A semelhança do nome "Casa Flores" entre as duas pinturas levou a uma pesquisa sobre o recém encontrado retrato da Marquesa. No próprio livro há uma referência de que o retrato pertenceu à Boehler Callery em Munique. ${ }^{6}$

6 MORET, Aureliano de Beruete. Coya as Portrait Painter. Houghton Mifflin Company: Boston e Nova lorque, 1922. 
No catálogo de uma exposição de 1941, realizada no Instituto de Arte de Chicago, com o nome The Art of Coya, consta uma obra em exibição com o mesmo nome de Retrato da Marquesa de Casa Flores, como um empréstimo da Galeria Paul Drey, de Nova Iorque. ${ }^{7}$ Com a consulta do catálogo, verificou-se que a imagem apresentada como o retrato da "Marquesa de Casa Flores" é uma reprodução semelhante e com as mesmas dimensões da obra estudada no projeto e presente no MASP, com o nome de O Retrato da Condessa de Casa Flores. A obra foi encontrada também em outro livro sobre o pintor. Francisco de Goya, escrito por August L. Mayer e publicado em 1923; na lista de pinturas ao fim do tomo, se encontra no número 230 o nome Die Marquesa de Casa-Flores, com as mesmas dimensões do quadro estudado. Ao citar os nomes de coleções as quais a pintura fez parte, Mayer localiza os seguintes nomes: "Madrid: D. Aureliano de Beruete; München: Julius Böhler; Budapest: Marcell von Nemes, Baron M. Herzog".

Por meio de visitas ao MASP foram encontrados documentos referentes à obra. Dentre estes, foi possível catalogar cartas, cromos, telegramas, recortes de jornais, pedidos de reprodução, cartões postais, dados sobre empréstimos, reproduções, divulgações da pintura, informações sobre a dupla nomeação de Marquesa/Condessa, biografia da retratada e documentos sobre o valor de aquisição da obra. Com a junção do trabalho de pesquisa e documentos disponíveis no museu em que se encontra, foi possível reconstruir o começo da trajetória do quadro até sua doação ao MASP. Os dados se mostraram essenciais para a construção de uma linha do tempo de movimentação da pintura, estruturada na tabela abaixo; porém, os documentos não mencionam as datas em que o retrato se deslocou entre coleções. Algumas datas foram localizadas na consulta da bibliografia pesquisada.

Tabela 1 - Coleções

\begin{tabular}{|l|c|c|}
\hline \multicolumn{1}{|c|}{ Local } & Data de entrada & Data de saída \\
\hline Madrid, Coleção Marquesa de Casa-Flores . & Desconhecida & Desconhecida \\
\hline Collezione Aureliano De Beruete, Madrid. & 1903 & Desconhecida \\
\hline Böhler Gallery, Munique. & 1922 & Desconhecida \\
\hline Coleção M. Von Nemés, Budapeste. & Desconhecida & Desconhecida \\
\hline Caleria Paul Drey & 1941 & Desconhecida \\
\hline Coleção Barão M. Herzog, Budapeste. & Desconhecida & Desconhecida \\
\hline Coleção Privada, Londres. & Desconhecida & Desconhecida \\
\hline Acervo MASP & 03 de junho de 1949 & Atualmente \\
\hline
\end{tabular}

7 RICH, Daniel Catton (Ed.). The Art of Coya paintings, drawings and prints (catálogo de exposição). The Art Institute of Chicago, 1941. 
A partir análise dos documentos encontrados no museu em conjunto com o trabalho de pesquisa, foi possível organizar, igualmente, uma cronologia de exposições das quais a obra fez parte, como apresenta a segunda tabela. Percebe-se que logo após sua chegada no Museu de Arte de São Paulo, a obra fez parte de algumas exposições internacionais; nos últimos anos foram encontrados, por ora, apenas aparições em exposições nacionais, totalizando 10 participações até o momento.

Tabela 2 - Exposições

\begin{tabular}{|c|c|c|}
\hline Local & Data de entrada & Data de saída \\
\hline The Art of Goya, Art Institute, Chicago, n57. & 30 de janeiro, 1941 & 4 de março, 1941 \\
\hline $\begin{array}{l}\text { Some Masterpieces of European Art, The Museum of Fine Arts } \\
\text { Gothenburg. }\end{array}$ & Maio, 1947 & Junho, 1947 \\
\hline Acervo MASP. & o3 de junho de 1949 & Atualmente \\
\hline Exposição do Museu de L'orangerie. & 1953 & Desconhecida \\
\hline Exposição patrocinada por The Mainichi Newspapers, Japão. & 1978 & Desconhecida \\
\hline Exposição Museu de Arte Moderna da Bahia. & 18 de março de 1980 & Desconhecida \\
\hline Exposição de reproduções de Goya em Alicante, Espanha. & 1996 & Desconhecida \\
\hline $\begin{array}{l}\text { Exposição “Mirar y ser visto: De Tiziano a Picasso. El retrato en la } \\
\text { colección del Masp", Fundación MAPFRE, Madri. }\end{array}$ & 07 de outubro de 2009 & $\begin{array}{l}20 \text { de dezembro de } \\
2009\end{array}$ \\
\hline $\begin{array}{l}\text { MASP Apresenta: O triunfo do detalhe - Os mestres antigos: o } \\
\text { retrato, MASP, São Paulo. }\end{array}$ & O2 de novembro de 2012 & 25 de novembro 2012 \\
\hline CCBB, Mostra Entre Nós, & 26 de abril de 2017 & O2 de julho de 2017 \\
\hline $\begin{array}{l}\text { Exposição Entre Nós - A figura humana no acervo do MASP, CCBB, } \\
\text { Rio de Janeiro. }\end{array}$ & ०8 de fevereiro de 2017 & 10 de abril de 2017 \\
\hline Acervo em Transformação, MASP, São Paulo. & Dezembro de 2015 & Atualmente \\
\hline
\end{tabular}

\section{A Condessa de Casa Flores}

Ao longo da pesquisa, foi possível descobrir a identidade da retratada Condessa de Casa Flores, até então reconhecida apenas por seu título. Seu nome é María Rafaela Gutierrez de Terán, nascida em 12 de junho de 1771, na cidade do México, com data de falecimento desconhecida. María foi filha de Gabriel Gutiérrez de Terán e Josefa González-Guerra Vértiz. Foi esposa do conde de Casa Florez, embaixador da Espanha em Viena e São Petesburgo, José Antonio Florez Pereyra, a união ocasionou em sua mudança de nome e adição de título de Condessa. O casamento ocorreu em 7 de Maio de 1789, no Real Palácio na Cidade do México.

Em seu casamento, María Rafaela teve quatro filhos: Rafael Florez Gutiérrez de Terán (03/01/1794-?), Juan Bautista Maria Florez y Gutiérrez de Terán (10/04/1791-09/05/1871), José Flórez 
Gutiérrez de Terán (15/02/1790-28/03/1857) e María del Pilar Florez y Gutiérrez de Terán. ${ }^{8}$ Com a observação das datas de nascimento de seus filhos e a datação do quadro feita pelo MASP, percebe-se uma possibilidade da retratada estar grávida no momento em que o quadro foi pintado, de Juan Bautista ou Rafael. A vestimenta solta, de cor clara, que recobre a silhueta da Condessa sem ressaltar nenhuma parte de sua figura, em conjunto com a faixa rosa localizada abaixo do busto - único acessório no corpo da figura que acentua algum aspecto de sua constituição, deixam a interpretação de uma possibilidade de gravidez.

\section{Questões de atribuição}

No decorrer da pesquisa, encontraram-se algumas questões sobre a atribuição do Retrato. O artigo que introduziu a questão à pesquisa foi Agustín Esteve and Goya, escrito por Martin Sebastián Soria, no qual, o autor aborda a questão da autoria de retratos feitos pelo ajudante de Francisco de Goya, Agustín Esteve. Segundo Soria, alguns retratos atribuídos a Coya teriam sido feitos, na verdade por seu ajudante. A questão se tornou importante para a pesquisa pois, dentre os retratos citados por Soria, se encontra o objeto de estudo desta, Retrato da Condessa de Casa Flores. O autor afirma que ao comparar o referido retrato à pintura Josefa Castilla Portugal de Garcini, feita por Goya, a questão da autoria se torna clara pois Coya teria modelado uma beleza "Rubenesca" de grande realidade, com uma "pele transparente e quente, uma boca opulenta, sensível, nariz respirando, e habilmente esboçado, olhos expressivos. A modelo de Esteve é de madeira por comparação, todos os detalhes são desenhados do que pintados, especialmente os olhos ordenadamente circulares e a boca apertada, expressões que seriam típicas suas". 9

O nome de Soria também aparece em dois documentos presentes na no Masp: primeiro, em uma carta do Departamento de Serviços de Informação da Universidade do Estado de Michigan, de 25 de março de 1958, onde o livro "Augustin Esteve and Goya" escrito por ele em 1943 é citado como uma expansão de seu artigo, abordando com melhor ênfase as pinturas consideradas por ele realizadas por Esteve. O segundo documento é também uma carta, escrita pelo próprio Martin Soria, em 1954, direcionada ao Professor Pietro Maria Bardi. Na carta, Soria afirma que a Segunda Condessa de Casa Flores (não marquesa, pois tal título nunca haveria existido na Espanha), Maria Rafaela

\footnotetext{
8 Com exceção de María del Pilar Florez y Gutiérrez de Terán, que não possuí a data e local de nascimento conhecidos, todos os filhos de Rafaela nasceram na Cidade do México.

9 SORIA, Martin S. Augustín Esteve and Coya. In: The Art Bulletin, Vol. 25, No. 3 (Sep., 1943), pp. 249-250.
} 
Gutierrez de Teran, esposa do segundo Conde de Casa Flores, teve seu retrato pintado por Agustin Esteve entre 1795 e 1797. A questão de atribuição da obra não estava prevista no começo da pesquisa como um ponto de análise, porém, por sua evidente pertinência à mesma, se tornou um ponto de discussão dentro dela.

\section{Conclusão}

Em suma, essa apresentação pretendeu apresentar o início da pesquisa de iniciação científica sobre o Retratado da Condessa de Casa Flores que tenho desenvolvido. Uma grande parte deste primeiro momento de pesquisa foi destinada ao levantamento de informações sobre a obra, pois se trata de um retrato que não foi alvo de pesquisas empíricas até o momento, para compreender quem é a retratada e a construção de uma cronologia de deslocamentos da mesma, até a sua chegada ao Masp, com o adicional da questão de autoria encontrada ao longo da trajetória. O próximo momento da pesquisa será fundamentado pela análise da obra e comparação com as pinturas selecionadas, para o entendimento da representação da figura feminina por Francisco de Coya. 


\section{Referências bibliográficas}

AGUADO, Ana María, et al. Textos para la historia de las mujeres en España. Madrid, 1994.

BATICLE, Jeannine. Goya. Barcelona: Crijalbo Mondadori, 1995.

BRAY, Xavier. Coya: The Portraits. Londres: National Gallery Company Ltd, 2015.

CALVERT, Albert F. "Goya, an account of his life and works". J. Lane, Londres, 1908.

COLI, Jorge. O Sono da Razão Produz Monstros. In: Adauto Novaes. (Org). A Crise da Razão. São Paulo: Cia das Letras, 1996, p.301-313.

COLI, Jorge. Da luz e da sombra. In: O Corpo da Liberdade. São Paulo: Cosac Naify, 2010. pp. 19-34.

D'ORS, Eugenio. Coya El viviry el arte de Goya: Coya y lo Coyesco a la luz de la historia de la cultura. Madri: Libertarias/ Prodhufi, S.A., 1996.

DENISE, Flávia. Arte ao vivo. O Tempo, 08 de maio de 2017. Disponível em: <https://www.otempo.com.br/ opini\%C3\%A30/fl\%C3\%A1via-denise/arte-ao-vivo-1.1470608 >. Acesso em 03 de maio de 2019.

CASSIER, Pierre e Juliet Wilson. Coya: His life and Work. Londres, 1971.

GIANNINI, Alessandro. CCBB do Rio abre mostra com mais de cem obras do MASP. O Globo, o7 de fevereiro de 2017. Disponível em: <https://oglobo.globo.com/cultura/artes-visuais/ccbb-do-rio-abre-mostra-com-mais-cem-obras-do -masp-20884325>. Acesso em 03 de maio de 2019.

GLENDINNING, Nigel. Coya. Madrid: Arlanza, 2005.

. Goya's Patrons. In: Apollo Magazine, Vol. CXIV, No. 236 (Outubro de 1981).

Spanish Inventory References to Paintings by Coya, 1800-1850: Originals, Copies and Valuations. In: The Burlington Magazine, Vol. 136, No. 1091 (Feb., 1994), pp. 100-110.

COYA, Francisco de. Cartas a Martin Zapater. Editorial Istmo: Madrid, 1982.

GUDIOL, José. Goya. Barcelona: Ediciones Polígrafa, 2008.

. The Coya Exhibition at Chicago. In: The Art Bulletin. Vol 23, No. 2 (Jun, 1941), pp.169-170.

HACEN, Rainer. MARIE, Rose. Francisco Goya: 1746-1828. Colônia: Taschen, 2005.

HUCHES, Robert. Coya. São Paulo: Companhia das Letras, 2007.

KICZA, John E. The Great Families of Mexico: Elite Maintenance and Business Practices in Late Colonial Mexico. In: The Hispanic American Historical Review, Vol. 62, No. 3 (Agosto, 1982), pp. 429-457.

MASP Apresenta: $O$ triunfo do detalhe - os mestres antigos: o retrato. Arte ref., 8 de novembro, 2012. Disponível em: $<$ https://arteref.com/pintura/masp-apresenta-o-triunfo-do-detalhe-os-mestres-antigos-o-retrato/>. Acesso em 03 de maio de 2019.

MAYER, August L. Francisco de Goya. Editorial: München, F. Bruckmann, 1923.

MÉNDEZ, Elsaris Núñez. Female Society Portraits: representing the elite woman in eighteenth-century New Spain. Tese. Universidade de Illinois, Mestrado em História da Arte, 2012.

MORALES Y MARÍN, José Luis. Pintura en España. 1750-1808. Madrid: Cátedra, 1994.

MORET, Aureliano de Beruete. Coya as Portrait Painter. Houghton Mifflin Company: Boston e Nova lorque, 1922.

MULLER, Priscilla E. Coya's Portrait of Sabasa García. In: The Burlington Magazine, Vol. 135, No. 1079 (Fev., 1993), pp. 99101.

Discerning Coya. In: Metropolitan Museum Journal, Vol. 31, 1996, pp. 175-187.

O "Museu de São Paulo" em Paris Sessenta e Cinco telas, seguradas por 5.000.000 de dólares, estão expostas em Paris, no Museu de "L'orangerie". Correio da manhã, Sexta-feira 16 de outubro de 1953, ed. 18578. Disponível em: <http:// 
memoria.bn.br/DocReader/Hotpage/HotpageBN.aspx?bib=089842_06\&pagfis=30801\&url=http://memoria.bn.br/ docreader\# >. Acesso em 03 de maio de 2019.

PORTUS, Javier. The Spanish Portrait from El Greco to Picasso. Nova lorque: Scala Arts Publishers Inc, 2006.

RICH, Daniel Catton (Ed.). The Art of Coya paintings, drawings and prints (catálogo de exposição). The Art Institute of Chicago, 1941.

SALOMON, Xavier F. Goya and the Altamira Family. In: The Metropolitan Museum of Art Bulletin, Vol. 71, No. 4, 2014, pp. 1-2, 4-48.

SERRALLER, Francisco Calvo. Mujeres en el diván: Majas y Marquesas. In Fundación Amigos del Mueseo del Prado (ed.), Coya. Barcelona 2002.

SORIA, Martin S. Augustín Esteve and Goya. In: The Art Bulletin, Vol. 25, No. 3 (Sep., 1943), pp.239-266.

TRAPIER, Elizabeth du Gue. Goya and His Sitters: A Study of His Style as a Portraitist. The Hispanic Society of America, New York, 1964.

TODOROV, Tzvetan. Coya à sombra das Luzes. São Paulo: Companhia das Letras, 2014.

TOMLINSON, Janis (ed.). Coya Images of Women (catálogo de exposição). National Gallery of Art, Washington D.C. 2002. Nineteenth-Century Spanish Art. Madrid. The Burlington Magazine, Vol. 150, No. 1260 (Mar., 2008), pp. 204-206.

VALIATI, Leandro. Economia da Cultura em Perspectiva Institucional: Mecenato no Empresariado Urbano-Industrial Ascendente (1947-1960). Tese (Doutorado) - Universidade Federal do Rio Grande do Sul, Faculdade de Ciências Econômicas, Programa de Pós-Craduação em Economia, Porto Alegre, 2013.

VIRGílIO, Paulo. Parceria inédita leva ao Rio mostra de parte do acervo do MASP. Agência Brasil, o8 de fevereiro de 2017. Disponível em: <http://agenciabrasil.ebc.com.br/cultura/noticia/2017-02/parceria-inedita-traz-ao-rio-mostrade-parte-importante-do-acervo-do-masp>. Acesso em 03 de maio de 2019.

VON LOGA, Valerian. Francisco de Coya. G. Grote'sche Verlagsbuchhadlung, 1921. 